\title{
APPLICATIONS ON HIGH-ENERGY X-RAYS TO STRESS MEASUREMENTS OF THERMAL BARRIER COATINGS
}

\author{
KENJI SUZUKI ${ }^{\mathrm{a}, *}$ and KEISUKE TANAKA ${ }^{\mathrm{b}}$ \\ ${ }^{a}$ Faculty of Education and Human Sciences, Niigata University, \\ Igarashi-2-no-cho, Niigata, 950-2181, Japan; \\ ${ }^{\mathrm{b}}$ Department of Mechanical Engineering, Nagoya University, Furoh-cho, \\ Chikusa-ku, Nagoya, 464-8603, Japan
}

(Received 13 September 2003)

\begin{abstract}
High-energy X-rays from a synchrotron radiation source, SPring-8, were applied to the stress measurements of thermal barrier coating (TBC). The specimen had a zirconia top coat on a bond coat of NiCoCrAlY sprayed on the substrate of Ni-base super alloys. The stress in the bond coat was measured through the top coat using the diffraction of $\mathrm{Ni}_{3} \mathrm{Al} 311$ by high-energy X-rays with an energy of $72 \mathrm{keV}$. The $\sin ^{2} \psi$ method was used to determine the stress value. A specially designed furnace with a wide beryllium window was developed to conduct in-situ measurements of the internal stress in the bond coating at the room temperature, 773,1073 , and $1373 \mathrm{~K}$. The internal stress was tensile at the room temperature, and decreased with increasing temperature. At $1073 \mathrm{~K}$ or higher, the internal stress in the bond coat was released due to softening of the bond coat. The normal stress perpendicular to the coating surface of TBC was evaluated by a new hybrid method. Since the penetration depth of low-energy X-ray is very small around a few micrometers for zirconia, the stress value measured by the $\sin ^{2} \psi$ method is the in-plane stress, $\sigma_{1}$, and the stress perpendicular to the surface was zero. On the other hand, the penetration depth of high-energy X-rays is very deep, so the measured stress value will be the in-plane stress minus the out-of-plane stress, i.e. $\sigma_{1}-\sigma_{3}$. The normal stress perpendicular to the surface, $\sigma_{3}$, i.e. the spalling stress, was estimated from these two measurements. The specimens were exposed in air atmosphere at $1373 \mathrm{~K}$ for 500,1000 , and $2000 \mathrm{~h}$. The distribution of the spalling stress in the top coat was estimated by the hybrid method. The spalling stress near the interface to the bond coat changed to a large tension after long-time exposure.
\end{abstract}

Keywords: High-energy X-rays; Stress measurements; Thermal barrier coating

\section{INTRODUCTION}

The thermal efficiency of gas turbines is improved by combustion at high temperatures. Thermal barrier coatings (TBCs) protect the components of the gas turbine engine from high temperatures and are indispensable for high temperature operation of gas turbine engines. The TBC consists of zirconia top coating and NiCoCrAlY bond coating and is plasma-sprayed on Ni-base super alloy substrates. The TBC shows complex mechanical

*Corresponding author. Tel./Fax: +81-25-262-7087. E-mail: suzuki@ed.niigata-u.ac.jp 
behaviors because of a complicated multi-layer system with many pores and micro cracks (Socie and Rejda, 1999; Suzuki and Tanaka, 2000). Although a mismatch of thermal expansions between the top and the bond coating is mainly responsible for residual stresses in the $\mathrm{TBC}$, the distribution of residual stresses in the $\mathrm{TBC}$ are difficult to predict due to complex microstrutures. During service at high temperatures, thermally grown oxide (TGO) is generated on the interface between top and bond coatings. The TGO promotes the spallation of TBCs, because the TGO induces the spalling stress into the top coating near the interface to the bond coating. In contrast to numerical studies (Pindera et al., 2002; Sfar et al., 2002), there are few experimental investigations being conducted on residual stresses in TBCs ( Scardi et al., 1998; Reimmer et al., 1999).

The X-ray diffraction method is one of the most powerful tools to measure the residual stress. When low-energy X-rays are used, it is impossible to measure the residual stress in the bond coating through the top coating. On the other hand, high-energy synchrotron X-rays have large X-ray penetration depth. Figure 1 shows the effective $\mathrm{X}$-ray penetration depth of the zirconia 333 diffraction calculated as a function of the X-ray energy and $\sin ^{2} \psi$ ( $\psi$ : tilt angle). Using high-energy synchrotron X-rays, the internal stress in the bond coating and the spalling stress in the top coating near the interface can be estimated. It will be possible to measure the spalling stress near the interface between top and bond coatings generated by TGO.

In the present article, two applications of high-energy synchrotron X-rays to TBCs are described. First, the internal stress in the bond coating was measured in situ through the top coating in the range from the room temperature to $1373 \mathrm{~K}$. Second, a new hybrid method was proposed for estimating the distribution of the spalling stress in the oxidized TBC.

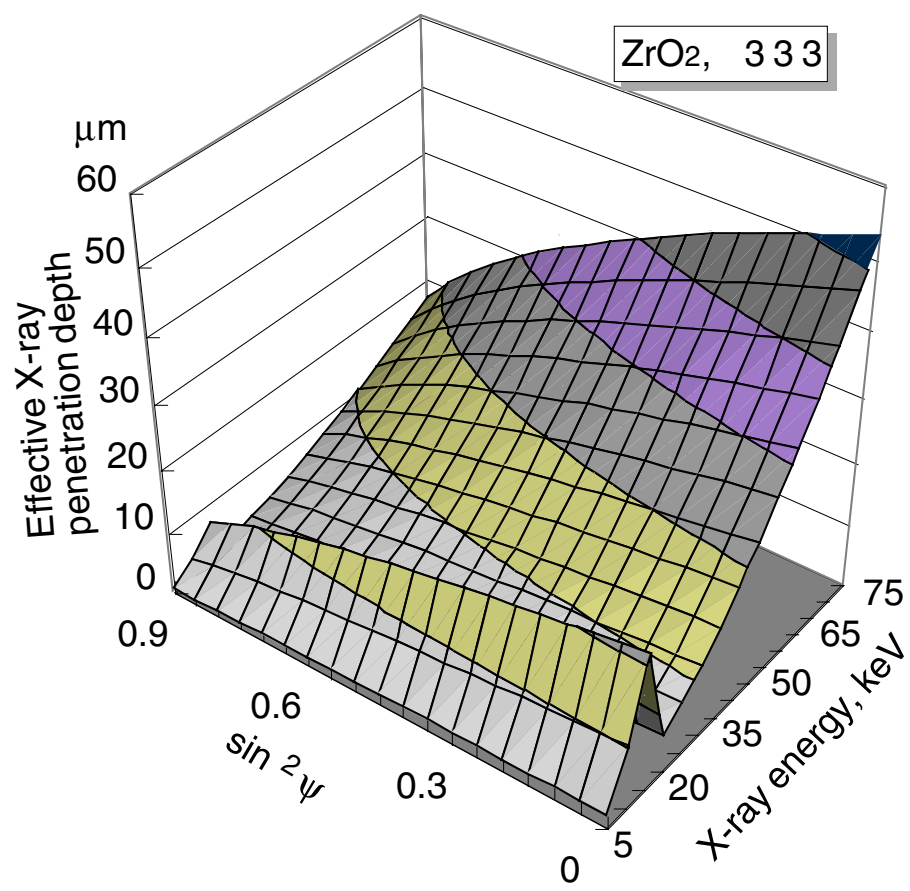

FIGURE 1 Effective X-ray penetration depth of 333 diffraction of zirconia. 


\section{IN-SITU MEASUREMENT OF INTERNAL STRESS IN BOND COATING AT HIGH TEMPERATURES}

\subsection{Experimental Procedure}

The bond coating made of NiCoCrAlY was low-pressure plasma-sprayed on a Ni-base super-alloy substrate. The thickness of the bond coating was $0.2 \mathrm{~mm}$. The top coating of zirconia with 8 mass $\%$ yittria was made by air plasma-spraying on the bond coating. The thickness of the top coating was $0.24 \mathrm{~mm}$. After heating TBCs in vacuum, the TBC was cut into the specimen with the dimensions of $8 \mathrm{~mm}$ in width and $60 \mathrm{~mm}$ in length.

The mechanical Young's modulus of the top coating was measured by the tension test of the free-standing top coating which was removed from the TBC specimen by electropolishing. The details of the tension test are described in our previous paper (Suzuki and Tanaka, 2000). The value of Young's modulus was $87.0 \mathrm{GPa}$ and the tensile strength was $7.88 \mathrm{MPa}$. To measure the mechanical Young's modulus of the bond coating, the free-standing bond coating specimen with the thickness of $1 \mathrm{~mm}$ was made by grinding off the substrate. The tension test of the free-standing bond coating specimen was performed with the tension tester, and the strain was measured with a strain gauge. The measured values of Young's modulus and Poisson's ratio were $158 \mathrm{GPa}$ and 0.27 , respectively.

The experiments by high-energy X-rays were performed with a 4-circle goniometer at the beam line BL02B1 in the Japan synchrotron research institute, SPring-8. For the stress measurement of the bond coating, the diffraction from $\mathrm{Ni}_{3} \mathrm{Al} 311$ was used. The stress constant at the room temperature was calculated from X-ray elastic constants determined in the previous study (Suzuki et al., 2002). The stress constant for each high temperature was calculated from the stress constant at the room temperature by taking into account the temperature dependence of Young's modulus. In measuring the internal stress, the specimens were rotated in order to ensure the equi-biaxial stress state. The stress was determined by the $\sin ^{2} \psi$ method with the side-inclination configuration ( $\psi$-goniometer).

The X-ray energy was $72.83 \mathrm{keV}$. The diffraction angle of $\mathrm{Ni}_{3} \mathrm{Al} 311$ is $9.0135^{\circ}$. The long soller slit was attached in front of the scintillation counter in order to reduce the broadening of diffraction profiles. The sampling time was set long enough to obtain the peak height above 3000 counts.

A specially designed furnace was developed in order to conduct in-situ measurement of internal stresses at high temperatures. Figure 2 is a photograph of the furnace attached to the diffractometer. This furnace has a wide window of beryllium for the stress measurement with the $\sin ^{2} \psi$ method where the values of $\sin ^{2} \psi$ are changed from 0 to 0.5 with an interval of 0.1 . The furnace can heat the specimen to $1473 \mathrm{~K}$. In the experiment, the internal stress in the bond coating was measured in air at the room temperature, 773,1073 , and $1373 \mathrm{~K}$.

\subsection{X-ray Diffraction Profiles of Thermal Barrier Coating}

First, the diffraction profiles of the TBCs were measured by synchrotron X-rays at the room temperature and high temperatures. Figure 3 shows the profiles obtained. The diffraction from the bond coating can be detected through the top coating with the thickness of $0.24 \mathrm{~mm}$. The NiCoCrAlY bond coating consists of $\mathrm{Cr}$ phase 


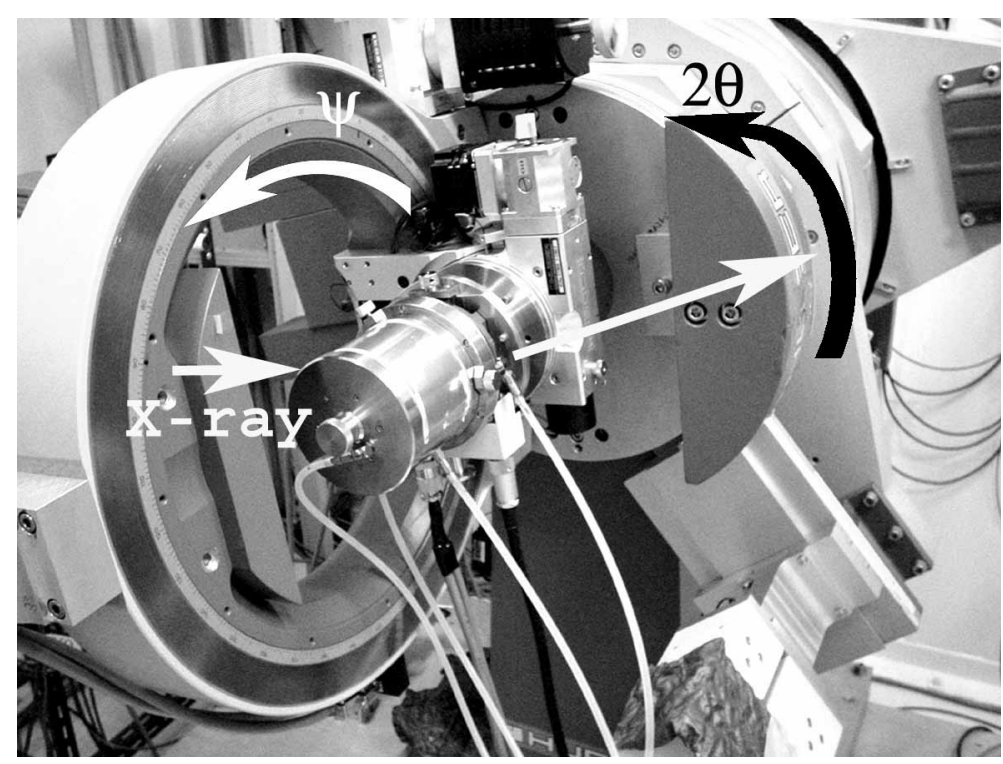

FIGURE 2 Furnace for in-situ stress measurement.

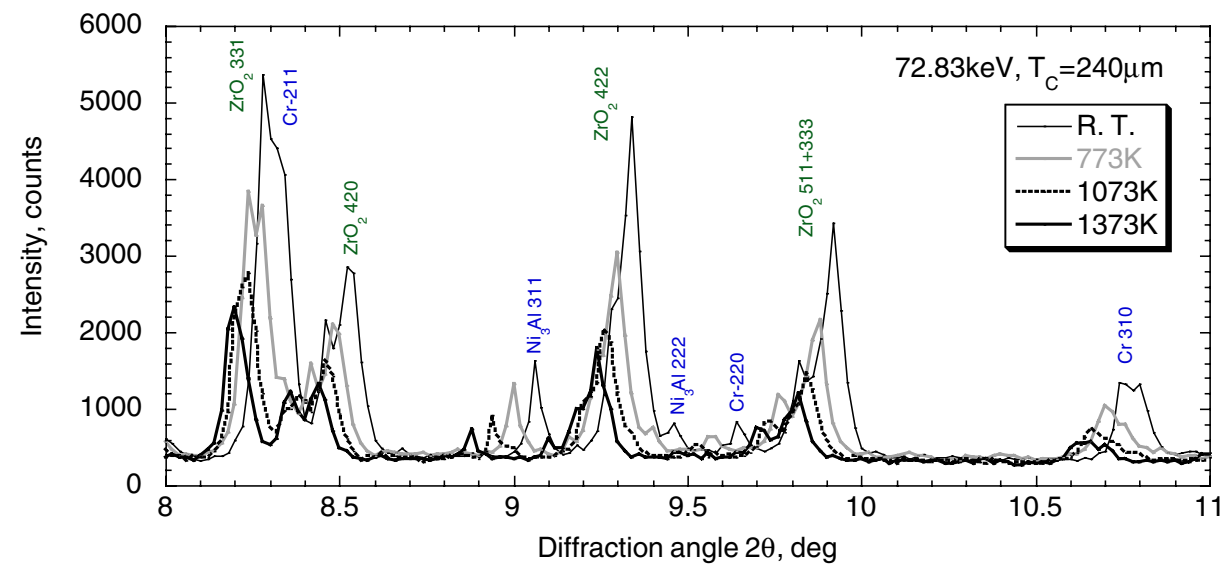

FIGURE 3 Diffraction profiles of thermal barrier coatings.

and $\mathrm{Ni}_{3} \mathrm{Al}$ phase (Suzuki et al., 2002). The diffraction from $\mathrm{Ni}_{3} \mathrm{Al} 311$ shows a strong peak and this peak has enough counts for stress measurements. The peak height of $\mathrm{Ni}_{3} \mathrm{Al} 311$ diffractions decreased with the increase in temperature because of thermal vibration.

\subsection{Change of Internal Stress in Bond Coating with Temperatures}

The internal stress in the bond coating was measured in situ using the furnace with highenergy synchrotron X-rays at high temperatures. The results are shown in Fig. 4. For the thickness of the top coating, $T_{C}=240 \mu \mathrm{m}$, the internal stress in the bond coating was a large tension at the room temperature. The internal stress decreased with the increase 


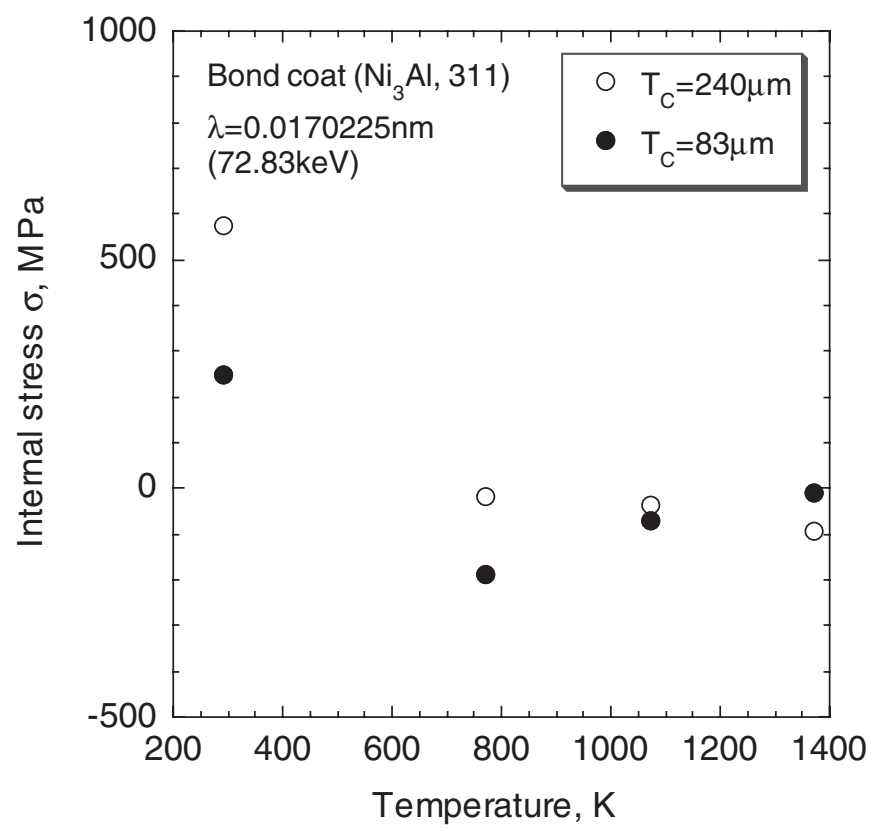

FIGURE 4 Change in internal stress of bond coating with change in temperature.

in temperature. At $1073 \mathrm{~K}$ and higher, the internal stress in the bond coating was released due to softening of the bond coating. The change of the internal stress in the bond coating can be explained by the difference in the thermal expansion between the top and bond coatings. The coefficient of thermal expansion of the bond coating is larger than that of the top coating. The bond coating has tensile stress by cooling and the tensile stress in the bond coating decreases by heating.

The specimen with the top coating of thickness, $T_{C}=87 \mu \mathrm{m}$, shows a similar change in internal stress like the specimen with $T_{C}=240 \mu \mathrm{m}$. The magnitude of the tensile stress in the bond coating of the former specimen is small, because the top coating is thinner than the bond coating.

\section{ESTIMATION OF SPALLING STRESS OF OXIDIZED THERMAL BARRIER COATINGS}

\subsection{Hybrid Method for Estimating Spalling Stress}

The spalling stress was determined by a new hybrid method described below. The coordinate system and the principal stress used are defined as shown in Fig. 5, where $\sigma_{X}$ is a stress to be measured by the X-ray method, and $\psi$ is the angle between the normal to the specimen surface and the normal to the diffraction plane. The relation between the measured diffraction angle, $2 \theta$, and the stresses is expressed as (Hauk, 1997)

$$
2 \theta=2 \theta_{0}-\frac{2\left(1+v_{X}\right)}{E_{X}} \tan \theta_{0}\left(\sigma_{X}-\sigma_{3}\right) \sin ^{2} \psi-\frac{2}{E_{X}} \tan \theta_{0} \sigma_{3}+\frac{2 v_{X}}{E_{X}} \tan \theta_{0}\left(\sigma_{1}+\sigma_{2}\right)
$$




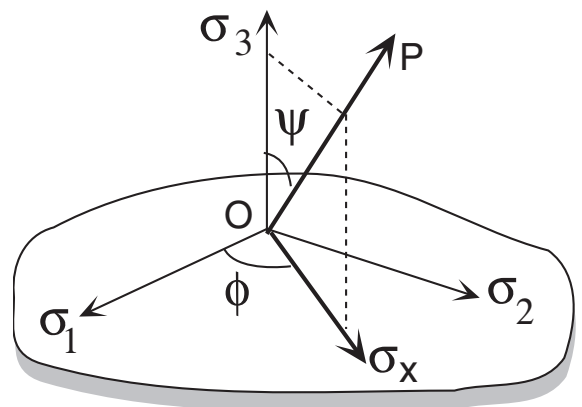

FIGURE 5 Coordinate system for X-ray stress measurement.

where $\theta_{0}$ is the diffraction angle for strain-free material, $E_{X}$ and $v_{X}$ are the X-ray values of Young's modulus and Poisson's ratio, respectively. Assuming $\sigma_{1}=\sigma_{2}=\sigma_{X}$, Eq. (1) is rewritten as follows:

$$
2 \theta=2 \theta_{0}-\frac{2\left(1+v_{X}\right)}{E_{X}} \tan \theta_{0}\left(\sigma_{1}-\sigma_{3}\right) \sin ^{2} \psi-\frac{2}{E_{X}} \tan \theta_{0} \sigma_{3}+\frac{4 v_{X}}{E_{X}} \tan \theta_{0} \sigma_{1}
$$

When low-energy X-rays are used, the X-ray penetration depth is very shallow and the measured stress is the plane stress state. Therefore, an out-of-plane stress, $\sigma_{3}$, is zero. We can obtain the following equation by a partial differentiation of Eq. (2) by $\sin ^{2} \psi$.

$$
\frac{\partial 2 \theta}{\partial \sin ^{2} \psi}=-\frac{2\left(1+v_{X}\right)}{E_{X}} \tan \theta_{0} \sigma_{1}
$$

Hence, the in-plane stress, $\sigma_{1}$, can be determined from the gradient of the $2 \theta-\sin ^{2} \psi$ diagram. The X-ray stress, $\sigma_{\mathrm{x} \text {-ray }}$ is equal to the in-plane stress as

$$
\sigma_{\mathrm{x}-\mathrm{ray}}=\sigma_{1}
$$

When the stress is measured by high-energy $\mathrm{X}$-rays, the stress state is no longer plane stress because of its large penetration depth. If the spalling stress exists near the interface between top and bond coatings, the gradient of the $2 \theta-\sin ^{2} \psi$ diagram measured with high-energy synchrotron $\mathrm{X}$-rays is

$$
\frac{\partial 2 \theta}{\partial \sin ^{2} \psi}=-\frac{2\left(1+v_{X}\right)}{E_{X}} \tan \theta_{0}\left(\sigma_{1}-\sigma_{3}\right)
$$

Thus, the stress measured by high-energy X-rays, $\sigma_{\text {syn }}$, is given by

$$
\sigma_{\mathrm{syn}}=\sigma_{1}-\sigma_{3}
$$

From the relation between Eqs. (4) and (6), the spalling stress, $\sigma_{3}$, is obtained by

$$
\sigma_{3}=\sigma_{\mathrm{x}-\text { ray }}-\sigma_{\mathrm{syn}}
$$


The method to estimate the spalling stress, $\sigma_{3}$, by combining $\sigma_{1}$ measured by low-energy $\mathrm{X}$-rays and $\sigma_{1}-\sigma_{3}$ measured by high-energy X-rays, is named as the hybrid method in this study. In the following analysis, the change in the X-ray penetration depth with the $\psi$ angle, however, is not taken into account for the sake of simplicity.

\subsection{Experimental Procedure}

The TBC specimens were made by the following process. The NiCoCrAlY powder was air plasma-sprayed on a $\mathrm{Ni}$ base super-alloy substrate as the bond coating, where the thickness of the bond coating was $0.15 \mathrm{~mm}$. The zirconia powder with 8 mass $\%$ yittria was air plasma-sprayed on the bond coating as the top coating. The thickness of the top coating was $0.3 \mathrm{~mm}$. To oxidize the TBC specimens, the specimens are exposed in air at $1373 \mathrm{~K}$ for 500,1000 , and $2000 \mathrm{~h}$.

The procedure for our hybrid method is illustrated in Fig 6. The distribution of the in-plane stress in the top coating, $\sigma_{1}$, is obtained by repeating the $\mathrm{X}$-ray stress measurement on the removed surface with low-energy X-rays. On the other hand, the surface layer of the top coating was removed by buffing with diamond slurry, and the specimens with several thicknesses of the top coating were prepared. The thicknesses of the removed layer of the top coating were $0.1,0.15,0.20,0.25$, and $0.30 \mathrm{~mm}$. The out-of-plane stress, $\sigma_{1}-\sigma_{3}$ for each surface-removed specimen was measured by high-energy synchrotron X-rays, and the depth distribution of $\sigma_{1}-\sigma_{3}$ was obtained. The distribution of the spalling stress, $\sigma_{3}$, is estimated using Eq. (7).

The in-plane stresses, $\sigma_{1}$, were measured using the $\sin ^{2} \psi$ method. The $\mathrm{ZrO}_{2} 133+331$ diffraction with $\mathrm{Cr}-\mathrm{K} \alpha$ radiations was used, and the diffraction angle $2 \theta_{0}$ was $153.82^{\circ}$, the stress constant is $-229 \mathrm{MPa} / \mathrm{deg}$. The values of $\sin ^{2} \psi$ were set from 0 to 0.6 with a step of 0.05 .

The experiment by high-energy X-rays was performed with the 4-circle goniometer at the beam line BL19B2 in SPring-8. The out-of-plane stress, $\sigma_{1}-\sigma_{3}$, was measured using synchrotron X-rays with $71.86 \mathrm{keV}$. The diffraction from $\mathrm{ZrO}_{2} 333+511$ was used and

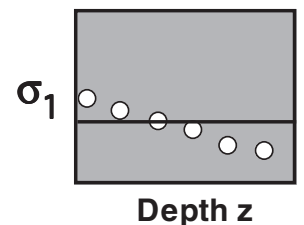

Depth z

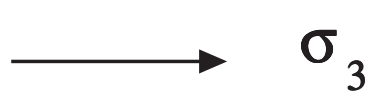

3

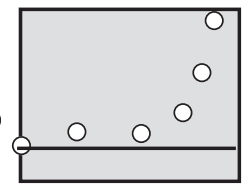

Depth z
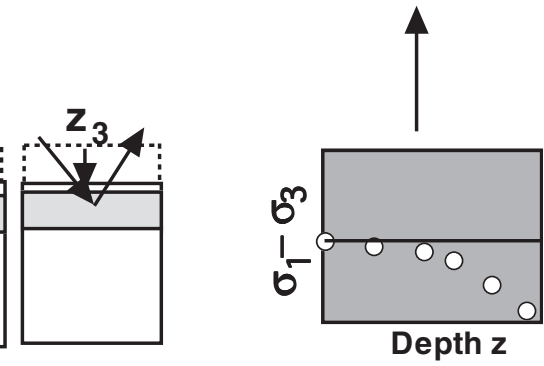

Removed specimens

FIGURE 6 Procedure of hybrid method to estimate the spalling stress. 
its diffraction angle, $2 \theta_{0}$, was $10.029^{\circ}$. The values of $\sin ^{2} \psi$ were set from 0 to 0.7 with a step of 0.1 . The peak position of the diffraction angle was determined by the $2 / 5$ value breadth. The stress constant used was $-11274 \mathrm{MPa} / \mathrm{deg}$. A long soller slit was attached front the scintillation counter in order to reduce the broadening of the diffraction profiles.

\subsection{Oxidation of Thermal Barrier Coatings}

When a TBC is exposed for a long time in air at high temperatures, the bond coating oxidizes. The cross section of the TBCs was observed with scanning electron microscopy. The micrographs of the TBCs As-sprayed and oxidized are shown in Figure 7. For the As-sprayed TBC, the TGO layer cannot be observed. For the TBC exposed at $1373 \mathrm{~K}$ for $1000 \mathrm{~h}$, the TGO layer appears clearly. As seen in the figure, the TGO layer exists on the interface between top and bond coatings. The TGO layer consists of the alumina layer colored black and the mixed oxide layer colored gray in the figure (Ogawa et al., 2001). The TGO layer becomes thick at the crest of the undulation of the interface and thin at the bottom of the interface undulation. The convex part of the bond coating oxidizes more easily compared with the concave part.

Figure 8 shows a micrograph of the oxidized TBC. In the figure, the top coating is the upper part, the bond coating is the lower part, and the TGO layer is the gray part

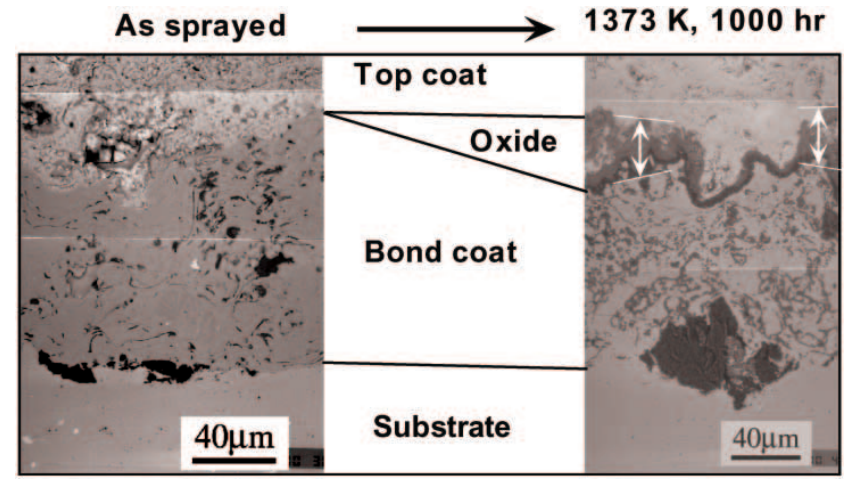

FIGURE 7 Micrograph of cross section of thermal barrier coatings.

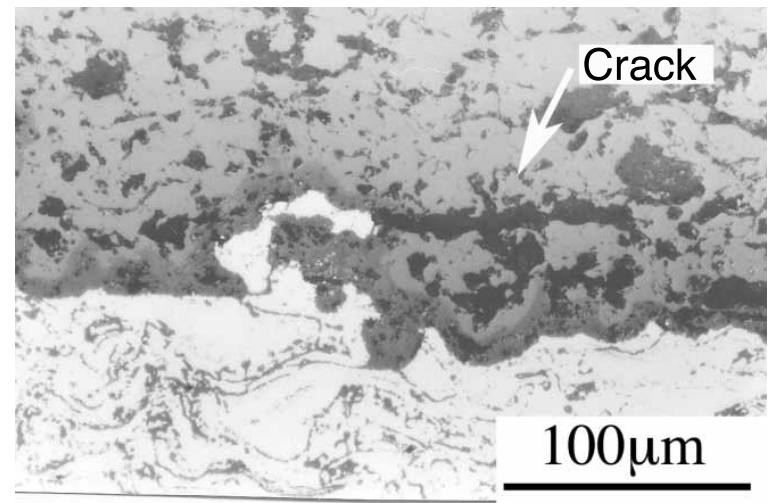

FIGURE 8 Micrograph of thermally grown oxide and spalling crack. 
between the top and bond coatings. The TGO at the crest of the interface undulation pushes the top coating up, and spalling cracks initiate from the convex part of the TGO. The TGO generates the spalling stress in the top coating. The spallation is the most serious problem for durability of TBC. The accurate determination of the spalling stress is the first step to improve the coating technology of TBCs.

\subsection{Estimation of Spalling Stress}

The distributions of the in-plane stress, $\sigma_{1}$, were measured, and the results are shown in Fig. 9. The in-plane stress in the top coating without oxidation is a small tension beneath the surface and nearly constant about $60 \mathrm{MPa}$ in the top coat to the interface. For oxidized TBCs, the in-plane stress was a very small tension just beneath the surface and changed into a compression beneath the surface layer. The in-plane stress of the oxidized top coating becomes a large compressive stress near the interface.

The out-of-plane stress in the top coatings, $\sigma_{1}-\sigma_{3}$, was measured with high-energy synchrotron X-rays, then the spalling stress, $\sigma_{3}$, was calculated by Eq. (7). The distribution of the spalling stress of the top coatings is shown in Fig. 10. The spalling stress at the surface was nearly zero in accordance with the assumption of a plane stress state. In the figure, the data are plotted at the depths from the surface, $z$, equal to the removal depth plus $40 \mu \mathrm{m}$, because the mean of the X-ray penetration depth is $40 \mu \mathrm{m}$. In the case of the removed depth of $300 \mu \mathrm{m}$, the data are plotted at $z$ equal to the removal depth plus $20 \mu \mathrm{m}$, where the value of $20 \mu \mathrm{m}$ is equivalent to the mean of the amplitude of the interface undulation.

For the TBC without oxidation, the spalling stress, $\sigma_{3}$, is very small tension from the surface to the interface between top and bond coatings. For oxidized specimens, the

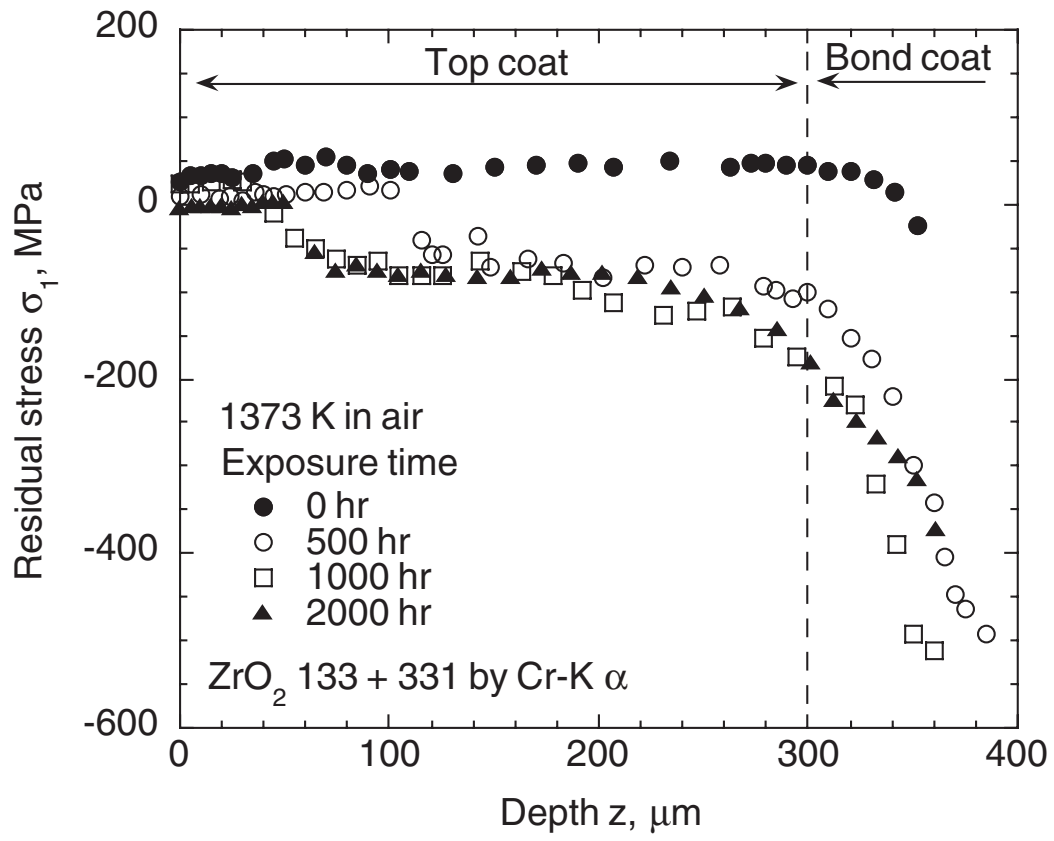

FIGURE 9 Distribution of in-plane stress in top coating. 


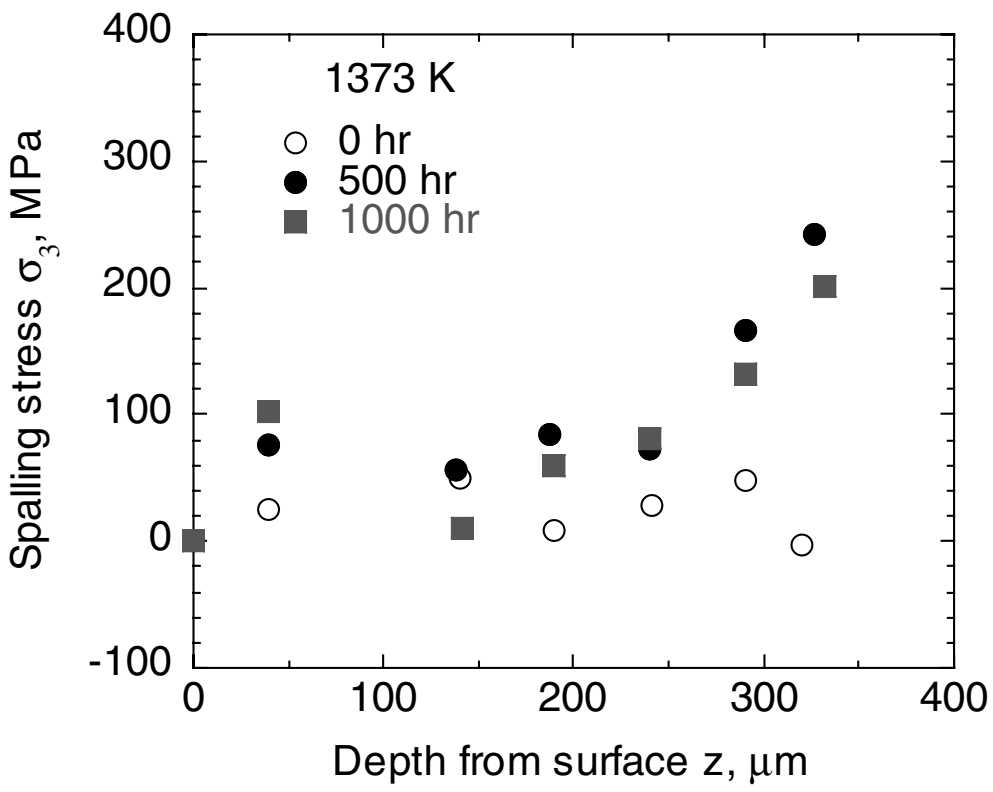

FIGURE 10 Distribution of spalling stress in top coating.

spalling stress is a small tension beneath the surface, but steeply increases to a large tension in the vicinity of the interface between top and bond coatings. There is no big difference in the spalling stress between the exposure times of 500 and $1000 \mathrm{~h}$.

According to the spalling stress estimated by the hybrid method, a large spalling stress is generated by the TGO especially near the interface. As a result, the spallation of the top coating occurs near the interface between top and bond coatings. This explanation corresponds to the micrograph of the spallation of the oxidized TBCs shown in Fig. 8. The spalling stress can be decreased by controlling the TGO. It is very important to protect the bond coating from oxidation. The hybrid method proposed in the present study is useful for estimating the spalling stress in the deep interface in multi-coatings like TBCs.

\section{CONCLUSIONS}

High-energy X-rays were applied to the stress measurements of the thermal barrier coatings. Using high-energy synchrotron X-rays, the internal stress in the bond coating was in-situ measured at high temperatures. A hybrid method was proposed to estimate the spalling stress in oxidized TBCs. The obtained results are summarized as follows:

1. The diffractions from the bond coating can be measured through the top coating with the thickness of $0.24 \mathrm{~mm}$ using high-energy synchrotron X-rays of $72 \mathrm{keV}$.

2. The internal stress in the bond coating was in-situ measured at high temperatures. The internal stress was a tension at the room temperature and decreased with the increase in temperature. At $1073 \mathrm{~K}$ and higher, the internal stress in bond coating was released due to softening of the bond coating. 
3. To estimate a spalling stress in TBCs, a hybrid method was proposed. The in-plane stress, $\sigma_{1}$, can be measured with low-energy X-rays, and the out-of-plane stress, $\sigma_{1}-\sigma_{3}$, can be measured by high-energy X-rays. By combining the measurements by two methods, the spalling stress can be estimated.

4. The in-plane stress in the top coating without oxidation was a small tension beneath the surface and maintained constant, and then decreased near the interface. The in-plane stress in the top coating with oxidation was a small tension beneath the surface and changed into a compression. The in-plane stress was a large compression near the interface.

5. The spalling stress was estimated by the hybrid method. For As-sprayed TBCs, the spalling stress was small in the top coating from the surface to the interface. For oxidized TBCs, the spalling stress was a small tension beneath the surface, but steeply increased near the interface. The spallation of oxidized TBCs can be expected from the spalling stress estimated with the hybrid method.

\section{Acknowledgments}

This work was supported financially by a grant in aid for science research from the ministry of education, culture, sports, science, and technology of Japan (No. 13650078). The synchrotron radiation experiments were performed at SPring- 8 with the approval of the Japan Synchrotron Radiation Research Institute (Proposal No. 2001B-0063-Ndnp, 2002A-0116-ND1-np, 2003A0161-NDM1-np and TU-3). The authors are obliged to Dr. N. Ikeda, Dr. I. Hirosawa, Dr. M. Sato (JASRI), K. Nishio, H. Okado and M. Kawamura (Kawasaki Heavy Industries, Ltd), T. Kubo (Toshiba, Ltd) for assistances of the experiments and for helpful suggestions.

\section{References}

Hauk, V. (1997) Structural and Residual Stress Analysis by Nondestructive Method, p. 139. Elsevier Science, Amsterdam.

Scardi, P., Leoni, M., Bertini, L., Bertamini, L. and Cernuschi, F. (1998) Strain gradients in plasma-sprayed zirconia thermal barrier coatings. Surface and Coating Technology, 108-109, 93-98.

Reimmer, W., Pyzalla, A., Broda, M., Brusch, G., Dantz, D., Schmackers, T., Liss, K.-D. and Tschentscher, T. (1999). The use of high-energy synchrotron diffraction for residual stress analysis. Journal of Materials Science Letters, 18, 581-583.

Socie, D. and Rejda, E. (1999). Cyclic deformation and fatigue of plasma sprayed thermal coatings. Fatigue '99, pp. 1905-1912. Higher Education Press, Beijing, China.

Suzuki, K. and Tanaka, K. (2000). X-ray study on deforemation mechanics of thermal barrier coatings. The 6th International Conference on Residual Stresses, Vol. 1, pp. 701-708. IOM communications, London.

Ogawa, K., Shoji, T., Aoki, H., Fujita, N. and Torigoe, T. (2001). Mechanistic understanding for degraded thermal barrier coatings. JSME International Journal Ser., A-44, 507-513.

Pindera, M.-J., Aboudi, J. and Arnold, S.M. (2002). Analysis of spallation mechanism in thermal barrier coatings with graded bond coats using the higher-order theory for FGMs. Engineering Fracture Mechanics, 69, 1587-1606.

Sfar, K., Aktaa, J. and Munz, D. (2002). Numerical investigation of residual stress fields and crack behavior in TBC systems. Materials Science and Technology, A333, 351-360.

Suzuki, K., Tanaka, K., Akiniwa, Y., Nishio, K., Kawamura, M. and Okado, H. (2002). Measurements of internal stresses in bond coating using high energy X-rays from synchrotron radiation source. Journal of Japanese Society for Synchrotron Radiation Research, 15, 347-353. 